\title{
Explant analysis of the Biomet Magnum/ ReCap metal-on-metal hip joint
}

\section{S. C. Scholes, B. J. Hunt, V. M. Richardson, D. J. Langton, E. Smith, T. J. Joyce}

Newcastle University, Newcastle, United Kingdom

- S. C. Scholes, BSc, PhD, Research Fellow,

- B. J. Hunt, MEng, Postgraduate Researcher,

V. M. Richardson, BSc, Research Coordinator,

n T. J. Joyce, BEng, MSc, MA, $\mathrm{PhD}$, Professor of Orthopaedic

Engineering, School of Mechanical and Systems Engineering, Newcastle University, Claremont Road, Newcastle-upon-Tyne, NE1 7RU, UK.

D. J. Langton, MRCS, PhD, Lead Clinical Scientist, Freeman Hospital, Newcastle-upon-Tyne, NE7 7DN, UK.

E. Smith, MBBCh, BSC

Consultant Orthopaedic Surgeon, Avon Orthopaedic Centre, North Bristol NHS Trust, Southmead Hospital, Westbury-on-Trym, Bristol, BS10 5NB, UK.

Correspondence should be sent to S. C. Scholes;

email: susan.scholes@ncl.ac.uk

doi: 10.1302/2046-3758.62.BJR2016-0130.R2

Bone Joint Res 2017;6:113-122. Received: 5 May 2016; Accepted: 8 December 2016

\section{Objectives}

The high revision rates of the DePuy Articular Surface Replacement (ASR) and the DePuy ASR $\mathrm{XL}$ (the total hip arthroplasty (THA) version) have led to questions over the viability of metalon-metal (MoM) hip joints. Some designs of MoM hip joint do, however, have reasonable mid-term performance when implanted in appropriate patients. Investigations into the reasons for implant failure are important to offer help with the choice of implants and direction for future implant designs. One way to assess the performance of explanted hip prostheses is to measure the wear (in terms of material loss) on the joint surfaces.

\section{Methods}

In this study, a coordinate measuring machine (CMM) was used to measure the wear on five failed cementless Biomet Magnum/ReCap/ Taperloc large head MoM THAs, along with one Biomet ReCap resurfacing joint. Surface roughness measurements were also taken. The reason for revision of these implants was pain and/or adverse reaction to metal debris (ARMD) and/or elevated blood metal ion levels.

\section{Results}

The mean wear rate of the articulating surfaces of the heads and acetabular components of all six joints tested was found to be $6.1 \mathrm{~mm}^{3} /$ year (4.1 to 7.6). The mean wear rate of the femoral head tapers of the five THAs was $0.054 \mathrm{~mm}^{3} /$ year $(0.021$ to 0.128$)$ with a mean maximum wear depth of $5.7 \mu \mathrm{m}$ (4.3 to 8.5).

\section{Conclusion}

Although the taper wear was relatively low, the wear from the articulating surfaces was sufficient to provide concern and was potentially large enough to have been the cause of failure of these joints. The authors believe that patients implanted with the ReCap system, whether the resurfacing prosthesis or the THA, should be closely monitored.

Cite this article: Bone Joint Res 2017;6:113-122.

Keywords: Hip, Arthroplasty, Wear, Metal-on-Metal, Taper, Film Thickness, Lubrication

\section{Article focus}

- How does the ex vivo wear of failed Biomet ReCap joints compare with that of similar MoM hip joint designs?

\section{Key messages}

- The wear rates of each of these THAs and surface replacement ReCap joints (4.1 to $7.6 \mathrm{~mm}^{3}$ /year) were higher than those considered to be able to cause wearrelated failures in similar large diameter monoblock MoM hips.
- The wear of the joints measured in this study was mainly found to be from the articulating surfaces.

\section{Strengths and limitations}

- The volumetric wear of the ReCap joint has been measured and is reported for the first time using a viable technique for both the articulating surfaces (of the THAs and the resurfacing) and the taper junctions of the THA.

- This paper reports on a relatively low sample size. 


\section{Introduction}

In an attempt to minimise the occurrence of failure of hip prostheses due to wear particle-induced osteolysis, there was a resurgence of metal-on-metal (MoM) hip joints between the mid 1990s and mid 2000s. ${ }^{1-3}$ These all-metal hip joints had a larger diameter than those that had been available in previous years in an attempt to optimise lubrication and the range of motion available for use, as well as reduce the incidence of dislocation. Larger diameter all-metal hips were often targeted at the younger, more active patient.

There were many designs of these large diameter $(\geqslant 36$ $\mathrm{mm}$ ) MoM hip joints and there was often the option to have either a surface replacement (hip resurfacing) joint or a total hip prosthesis. Some designs of MoM hip joint, such as the DePuy Articular Surface Replacement (ASR) and the ASR XL total hip arthroplasty (THA), have shown high rates of wear and revision. ${ }^{4-7}$ Many failures of these prostheses were attributed to adverse reaction to metal debris (ARMD). ${ }^{4}$ It has been suggested that the relatively shallow acetabular component used in both the ASR surface replacement and ASR XL predisposed the implant to edge wear. ${ }^{4}$ In addition to this, reports have been published discussing the taper wear of the ASR XL and the possibility of this taper wear being a contributing factor in the failure of MoM THAs. 6,8-10 The high rates of failure of the ASR and ASR $\mathrm{XL}$ are not alone among MoM hips. High revision rates have also been reported with the Zimmer Durom, ${ }^{11}$ the DePuy Pinnacle, ${ }^{12}$ and for the smaller diameter ( $\leqslant 46 \mathrm{~mm}$ ) Smith \& Nephew Birmingham Hip Resurfacing (BHR). ${ }^{13,14}$

This view has led to a reduction in the use of MoM hip prostheses, but there are still a variety of designs available. Some of these had acceptable mid-term performance in appropriate patients. ${ }^{15,16}$ Recently, in the United Kingdom, the acceptable survivorship for hip replacements given by the National Institute for Health and Care Excellence (NICE) has been changed from $90 \%$ at ten years to $95 \%$ at ten years. ${ }^{17}$

It is important to monitor the in vivo performance of all hip prostheses in order to protect the patients from further surgery by becoming more knowledgeable regarding those implants that are performing well, and those that are not.

One way to assess the performance of explanted hip prostheses is to measure the material loss from the bearing surfaces. ${ }^{18} \mathrm{~A}$ previous study has shown that wear volumes of a contemporary design of MoM hip joint higher than $2.3 \mathrm{~mm}^{3}$ per year can result in a wear-related failure of the prosthesis. ${ }^{6}$ Another paper stated "Wear rates above $1 \mathrm{~mm}^{3} /$ million cycles were consistent with metal ion levels above 10 ppm (sic), which may produce adverse reactions clinically". ${ }^{19}$

While many MoM hips have high revision rates, one study on the Biomet ReCap resurfacing MoM hip reported that "the Biomet ReCap and Magnum

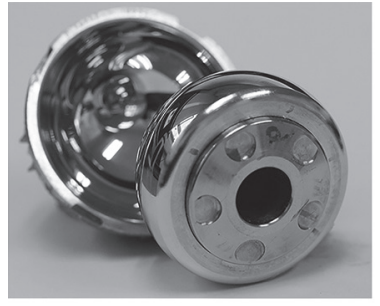

Fig. $1 \mathrm{a}$

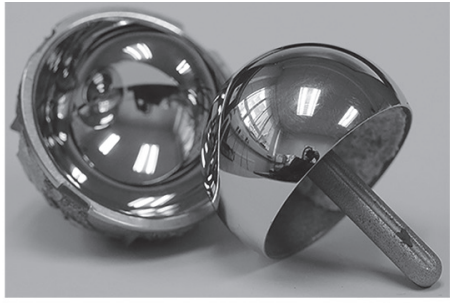

Fig. $1 \mathrm{~b}$ a) Biomet Magnum/ ReCap/ Taperloc large head MoM THA and (b) Biomet ReCap resurfacing hip joint.

components are not susceptible to the same design problems resulting in implant recall specific to the Durom and ASR prostheses". ${ }^{20}$

The aim of the study reported here was to use a coordinate measuring machine (CMM) to measure the wear (in terms of material loss) on failed Biomet Magnum/ ReCap/ Taperloc large head MoM THAs, along with a Biomet ReCap resurfacing joint. The articulating surface roughness of these explanted prostheses was also measured. The relationship between wear volume, roughness and failure was then explored.

\section{Patients and Methods}

Joints investigated. Between July 2006 and September 2011, 96 patients (110 hips) received the Biomet Magnum/ ReCap/ Taperloc large head MoM THA or the Biomet ReCap resurfacing hip joint as part of the "Magnum Total Hip System International Prospective Data Collection" study at North Bristol NHS Trust (Musculoskeletal Clinical Study 1939). Five patients (six hips) died but the cause of death was unrelated to the hip replacement. Ten patients (11 hips) were lost to followup, leaving 93 hips for analysis. A total of 19 patients (20 hips) received the resurfacing joint and 62 patients (73 hips) received the Magnum/ ReCap/ Taperloc THA. There were 38 females (46 hips) and 43 males (47 hips) in the cohort. The mean age at surgery was 57.9 years (26.8 to 73.8 ) and mean follow-up was 7.1 years (3.7 to 9.2). Eight hips (seven patients) were revised. Two early revisions were performed within the first month, one for a fractured neck of the femur in a resurfacing patient and one for early acetabular component rotation. Six revisions were performed between 31 and 92 months after index surgery; primary diagnosis was osteoarthritis. Written informed consent for retrieval of implants at time of revision was requested from the patient prior to any surgery. This complied with the European Community Regulations. The implant revised at 31 months was not available for investigation in this study.

Five cementless Biomet Magnum/ ReCap/ Taperloc large head MoM THAs and one Biomet ReCap resurfacing hip joint were investigated in this study (examples shown in Fig. 1). The resurfacing joint and four of the five THAs 
Table I. Clinical data for the explants measured in this study

\begin{tabular}{|c|c|c|c|c|c|c|c|}
\hline Implant & $\begin{array}{l}\text { Implant } \\
\text { diameter } \\
(\mathrm{mm})\end{array}$ & $\begin{array}{l}\text { Patient age } \\
\text { at primary } \\
\text { surgery (yrs) }\end{array}$ & $\begin{array}{l}\text { Time in vivo } \\
\text { (yrs) }\end{array}$ & $\begin{array}{l}\text { Acetabular component } \\
\text { inclination angle }\end{array}$ & Cobalt ( $\mu g / I)$ & $\begin{array}{l}\text { Chromium } \\
(\mu g / I)\end{array}$ & $\begin{array}{l}\text { Histology } \\
\text { (Yes/No) }\end{array}$ \\
\hline Resurfacing & 44 & 56.2 & 5.3 & NA & NA & NA & No \\
\hline THA Magnum 1 & 44 & 60.3 & 7.4 & $43^{\circ}$ & 4.75 & 4.57 & Yes \\
\hline THA Magnum 2 & 46 & 58.1 & 7.5 & $37^{\circ}$ & 13.8 & 16.5 & Yes \\
\hline THA Magnum 3 & 46 & 59.3 & 7.6 & $45^{\circ}$ & 4.75 & 4.57 & Yes \\
\hline THA Magnum 4 & 52 & 59.8 & 5.8 & $42^{\circ}$ & 1.96 & 2.48 & Yes \\
\hline THA Magnum 5 & 48 & 68.1 & 6.8 & NA & 18.1 & 13.8 & No \\
\hline
\end{tabular}

THA, total hip arthroplasty; NA, data not available

(THA Magnum 1 to 4: Table I) formed part of the prospective Bristol ReCap study. THA Magnum 1 and THA Magnum 3 were sequential bilateral revisions from the same patient. For the resurfacing joint and THA Magnum 1 to 4 , index and revision surgeries were performed at the Avon Orthopaedic Centre, North Bristol NHS Trust with revision undertaken between September 2012 and February 2014. For the joint labelled THA Magnum 5 in Table I, both the index and revision surgeries were performed at the Royal United Hospital Bath but by different surgeons. This implant was part of the retrieval study reported here, but is not part of the prospective Bristol ReCap study. Mean time in vivo for all of the implants was 6.7 years (5.3 to 7.6) (Table I). The mean age of the patients was 60.3 years (56.2 to 68.1) at primary surgery. The nominal implant diameters ranged from $44 \mathrm{~mm}$ to $52 \mathrm{~mm}$. Five of the implants were retrieved from female patients, one was from a male (THA Magnum 4).

All patients were revised for hip pain and/or investigations indicative of an ARMD and/or elevated blood metal ion levels. Prior to retrieval, blood was sampled from four patients (five hips) using a stainless steel 21-gauge needle (Becton Dickinson UK Ltd, Oxford, United Kingdom) and collected in a trace element tube that contained sodium ethylenediaminetetraacetic acid (EDTA). The samples were measured by inductively coupled plasma mass spectrometry (ICPMS) for whole blood. Cobalt (Co) and chromium ( $\mathrm{Cr}$ ) levels are represented in $\mu \mathrm{g} / \mathrm{l}$ (Table $\mathrm{I}$ ) and ranged from $1.96 \mu \mathrm{g} / \mathrm{l}$ to $18.1 \mu \mathrm{g} / \mathrm{l}$ for $\mathrm{Co}$, and 2.48 $\mu \mathrm{g} / \mathrm{l}$ to $16.5 \mu \mathrm{g} / \mathrm{l}$ for $\mathrm{Cr}$. In accordance with medicines and healthcare products regulatory agency guidelines, the blood metal ion levels in two patients were higher than $7 \mu \mathrm{g} / \mathrm{l}$ and identified as being at risk for metal-onmetal bearings. ${ }^{13}$ Further investigations were performed on three patients (four hips) using metal artefact reduction sequence (MARS) for magnetic resonance imaging (MRI). Evidence of a cystic collection or a soft-tissue mass further supported the presence of an ARMD in all four hips. The MARS MRI was not available in the other two patients. Finally, a positive histological analysis (examination of retrieved cellular tissue) of ARMD was confirmed as the diagnosis in four hips and the reason for failure. Histology was not available in two patients (the resurfacing joint and THA Magnum 5).
The bearing surfaces of the ReCap resurfacing are identical to those of the THA design. Both the resurfacing joint and THA were made from high carbon $(>0.2 \%)$ as-cast cobalt-chromium-molybdenum (CoCrMo). The radial clearance is specified as being between $75 \mu \mathrm{m}$ and 150 $\mu \mathrm{m}$ with sphericity of less than $5 \mu \mathrm{m}$. The femoral head extends approximately $23^{\circ}$ beyond a full hemisphere. The outside geometry of the acetabular component is hemispherical. The CoCr THA femoral head is designed to accept a tapered titanium (Ti) alloy sleeve. This Ti sleeve has an internal female taper and is used with a forged $\mathrm{Ti}$ Taperloc stem to give a $\mathrm{Ti} / \mathrm{Ti}$ taper/trunnion junction. These data are taken from the ReCap design rationale booklet. ${ }^{21}$ The acetabular component internal arc of cover ranges from $154.6^{\circ}$ for a $38 \mathrm{~mm}$ diameter implant to $163.6^{\circ}$ for the $60 \mathrm{~mm}$ diameter implant. ${ }^{20}$

All explanted joints were sterilised in $10 \%$ formaldehyde solution and cleaned thoroughly before being measured to determine wear volumes.

Equipment. The volumetric wear from the articulating surfaces (femoral head and acetabular component) of the six retrieved implants was measured on a CMM (Legex 322; Mitutoyo UK Ltd, Andover, United Kingdom) with an accuracy of $0.8 \mu \mathrm{m} .{ }^{8,18}$ The volumetric wear of the tapers of the five femoral heads from the Magnum/ ReCap/ Taperloc THAs was also measured on this CMM. No femoral stems were available for analysis. The CMM is a contacting instrument where a stylus is used to map the geometrical profile of the specimen surface. ${ }^{8,18} \mathrm{~A}$ custom-designed Matlab programme was used to provide the volumetric wear of the surfaces. The CMM and Matlab method have been shown to have an accuracy of approximately $0.5 \mathrm{~mm}^{3} 18,22$ for the wear measurements of the articulating surfaces, and $0.2 \mathrm{~mm}^{3}$ for the wear measurements of the tapers. ${ }^{8}$

In addition to the wear measurements, surface roughness measurements were taken on the articulating surfaces using a Zygo NewView 5000 non-contacting white light interferometric profilometer (Zygo Corporation, Middlefield, Connecticut). This has previously been used to measure the roughness of explanted MoM hips..$^{23-25}$ The $\times 10$ lens was used with a $\times 2$ zoom, giving an area of view of $317 \times 238 \mu \mathrm{m}$. The manufacturers of the NewView 5000 state that the vertical resolution of this profilometer 
is better than $1 \mathrm{~nm}$ with a $0.99 \mu \mathrm{m}$ lateral $(\mathrm{x}, \mathrm{y})$ resolution for the magnification used. Measurements of $S_{a}$ (mean surface roughness over the 3D area of view), $S_{q}$ (root mean square surface roughness over the $3 D$ area of view), and $S_{\text {sk }}$ (surface skewness over the 3D area of view) were taken. The skewness of a surface is a measure of symmetry of the profile about the mean line. A positively skewed surface has a predominance of peaks, and a negatively skewed surface has more pronounced valleys. All six heads and all six acetabular components were measured in the unworn region and the worn region. In order to determine the areas of the surfaces that were unworn and worn, the surfaces of these joints were visually inspected - this was then confirmed by images taken using the CMM. Ten measurements were taken within each region and the mean calculated.

Surface roughness measurements were also taken on the five femoral head tapers using a Mitutoyo Surftest SJ-210 (Mitutoyo Corporation, Kanagawa, Japan). Four 5 $\mathrm{mm}$ line profiles were taken at $90^{\circ}$ angles to each other. These profiles were taken in the region where the taper was engaged with the trunnion (as shown by the CMM measurements). The mean $R_{\mathrm{a}}$ (mean surface roughness of the $2 \mathrm{D}$ line profile) and $R_{\mathrm{q}}$ (root mean square surface roughness of the 2D line profile) values of these four roughness profiles were calculated for each of the five tapers.

Theoretical analysis. Theoretical studies were also performed. The predicted minimum film thickness using the theory by Hamrock and Dowson, ${ }^{26}$ along with the surface roughness measurements of the articulating surfaces, was used to calculate the theoretical lubrication regimes acting within the joints. ${ }^{27}$ These equations have been used previously in the calculation of the theoretical lubrication regimes of MoM joints, ${ }^{28}$ and the equations are given below.

The minimum film thickness equation: ${ }^{26}$

$$
\frac{h_{\min }}{R_{x}}=2.798\left(\frac{\eta u}{E^{\prime} R_{x}}\right)^{0.65}\left(\frac{L}{E^{\prime} R_{x}^{2}}\right)^{-0.21}
$$

$h_{\min }$ is the minimum film thickness, $R_{\mathrm{x}}$ is the equivalent radius for a ball on plane model (equation shown below), $\eta$ is the viscosity of the lubricant (taken as $0.010 \mathrm{~Pa} \mathrm{~s}$, a similar viscosity to pathological synovial fluid under the shear-thinning encountered during the stance phase of the walking cycle $\left.{ }^{29}\right), u$ is the entraining velocity $(0.012$ $\mathrm{ms}^{-1}$, again, during the stance phase of walking), $E^{\prime}$ is the equivalent elastic modulus of the material pairing (equation shown below; $2.3 \times 10^{11} \mathrm{~Pa}$ for $\mathrm{CoCrMo}$ ) and $L$ is the applied load (taken as $2000 \mathrm{~N}$ ).

The equivalent radius equation:

$$
\frac{1}{R_{x}}=\frac{1}{R_{h}}-\frac{1}{R_{c}}
$$

$R_{\mathrm{x}}$ is the equivalent radius, $R_{\mathrm{h}}$ is the radius of the femoral head and $R_{\mathrm{c}}$ is the radius of the acetabular component.

The equation for the equivalent elastic modulus:

$$
\frac{1}{E^{\prime}}=0.5\left\{\left(\frac{1-v_{1}^{2}}{E_{1}}\right)+\left(\frac{1-v_{2}^{2}}{E_{2}}\right)\right\}
$$

$v_{1}$ and $E_{1}$ are the Poisson's ratio and elastic modulus of the head $\left(0.3\right.$ and $\left.2.1 \times 10^{11} \mathrm{~Pa}\right)$ and $v_{2}$ and $E_{2}$ are the Poisson's ratio and elastic modulus of the component (0.3 and $2.1 \times 10^{11} \mathrm{~Pa}$ ).

Finally, the calculated minimum film thicknesses, together with the recorded mean values of average root mean square $S_{q}$ for the femoral head and acetabular component $\left(S_{\mathrm{qh}}\right.$ and $\left.S_{\mathrm{qc}}\right)$ for each joint, were used to determine the dimensionless parameter $\lambda$ and therefore the theoretical lubrication regimes acting within the joints. ${ }^{27}$

$$
\lambda=\frac{h_{\min }}{\left(S_{q h}^{2}+S_{q c}^{2}\right)^{0.5}}
$$

Previous work has shown that if the ratio of the minimum film thickness to the combined surface roughness is greater than one but less than three, mixed lubrication is likely. ${ }^{27}$ If $\lambda>3$ then a full-fluid film-lubricating regime is predicted, 27 i.e. the asperities of the bearing surfaces are completely separated by the lubricant film. A $\lambda$ value of less than one indicates boundary lubrication. ${ }^{27}$

\section{Results}

Wear of the articulating surfaces. Wear data for the articulating surfaces of the femoral head and acetabular component of each joint are shown in Table II, along with the radial clearances of the unworn sections (as measured on the CMM). These wear values are given as means because the data were found to be normally distributed using the Anderson-Darling test for normality $(p=0.918)$. The total wear volume for the head and the acetabular component of the THAs and resurfacing joint was between $30.0 \mathrm{~mm}^{3}$ and $57.3 \mathrm{~mm}^{3}$, and the volumetric wear rate was between $4.1 \mathrm{~mm}^{3} /$ year and $7.6 \mathrm{~mm}^{3} /$ year (mean: $6.1 \mathrm{~mm}^{3} /$ year). The mean volumetric wear rate measured for the five THAs was also $6.1 \mathrm{~mm}^{3} / y e a r$, with a range of 4.1 to $7.6 \mathrm{~mm}^{3} /$ year. The ReCap resurfacing hip joint provided a wear rate of $5.9 \mathrm{~mm}^{3} /$ year. In all cases, the femoral head wear volume was larger than the wear volume from the acetabular component. The mean femoral head:acetabular component wear ratio was 62:38 (54:46 to 69:31). Examples of the images obtained showing the wear profiles for the articulating surfaces of the femoral head and acetabular component are shown in Figure 2. The femoral head wear can be seen as being located close to the pole and the acetabular component 
Table II. Wear data for each hip joint

\begin{tabular}{|c|c|c|c|c|c|}
\hline \multirow[t]{2}{*}{ Joint } & \multirow{2}{*}{$\begin{array}{l}\text { Radial clearance } \\
\text { ( } \mu \mathrm{m})\end{array}$} & \multicolumn{2}{|l|}{ Wear $\left(\mathrm{mm}^{3}\right)$} & \multirow[t]{2}{*}{ Total wear $\left(\mathrm{mm}^{3}\right)$} & \multirow{2}{*}{$\begin{array}{l}\text { Wear rate }\left(\mathrm{mm}^{3} /\right. \\
\text { yr) }\end{array}$} \\
\hline & & Femoral head & Acetabular component & & \\
\hline Resurfacing & 84 & 21.1 & 10.0 & 31.1 & 5.9 \\
\hline THA Magnum 1 & 92 & 17.7 & 12.3 & 30.0 & 4.1 \\
\hline THA Magnum 2 & 120 & 31.0 & 26.3 & 57.3 & 7.6 \\
\hline THA Magnum 3 & 108 & 25.0 & 15.6 & 40.6 & 5.3 \\
\hline THA Magnum 4 & 98 & 26.3 & 14.6 & 40.9 & 7.1 \\
\hline THA Magnum 5 & 110 & 29.8 & 13.3 & 43.1 & 6.3 \\
\hline
\end{tabular}
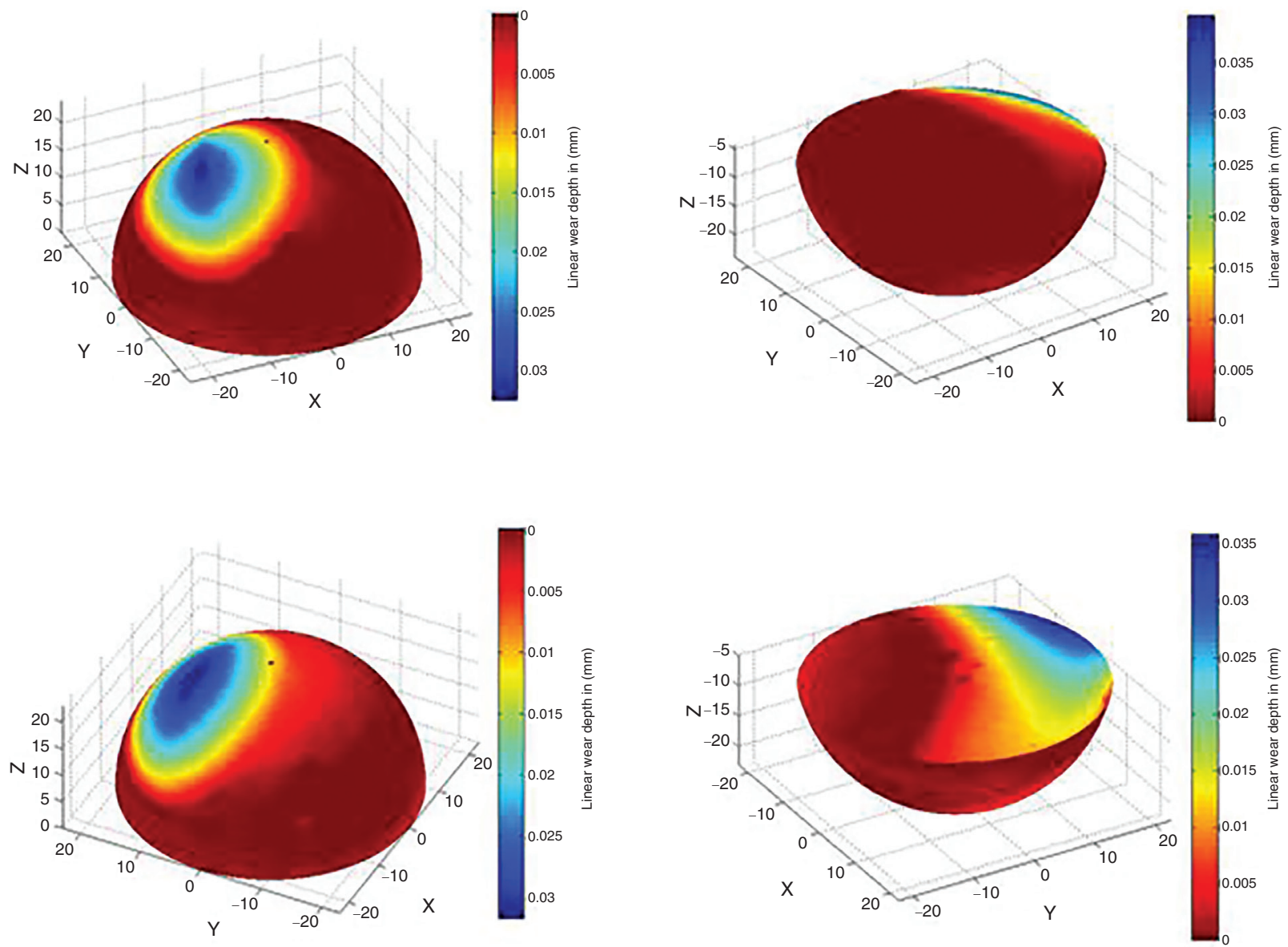

Fig. 2

Examples of worn images (blue/green) of areas on femoral head (left) and acetabular component (right) indicative of all joints measured in this study.

wear was mainly at the rim. The measured radial clearances were within the range given in the manufacturer's specifications. ${ }^{21}$

Surface roughness measurements of the articulating surfaces. The surface roughness measurements performed on the unworn and worn regions of the femoral heads and acetabular components are shown in Tables III and IV. It was not possible to distinguish an unworn area on the acetabular component of THA Magnum 3, therefore, no unworn measurements were available for this acetabular component. Figures 3 and 4 show examples of images acquired by the non-contacting profilometer on the unworn (a) and worn (b) regions of the femoral heads and acetabular components, respectively.

Theoretical lubrication regimes. Using the equations for predicted minimum film thickness, $h_{\min }$, and the dimensionless parameter, $\lambda$, the theoretical lubrication regime acting within each joint during the stance phase of the walking cycle was calculated. Table $V$ shows the predicted lubrication regimes for each joint using the surface roughness values obtained in the unworn region and the worn region of each component. 
Table III. Surface roughness $\left(S_{a}, S_{\mathrm{qh}}\right.$ and $\left.S_{\mathrm{sk}}\right)$ results for the six femoral heads in the unworn and worn regions

\begin{tabular}{|c|c|c|c|c|c|c|}
\hline \multirow[t]{2}{*}{ Joint } & \multicolumn{2}{|l|}{$S_{a}(\mu m)$} & \multicolumn{2}{|l|}{$S_{q h}(\mu m)$} & \multicolumn{2}{|l|}{$S_{\text {sk }}$} \\
\hline & Unworn & Worn & Unworn & Worn & Unworn & Worn \\
\hline Resurfacing & $0.048(0.006)$ & $0.022(0.011)$ & $0.064(0.007)$ & $0.043(0.022)$ & $1.112(0.613)$ & $0.277(1.411)$ \\
\hline THA Magnum 1 & $0.006(0.000)$ & $0.019(0.010)$ & $0.011(0.003)$ & $0.037(0.021)$ & $1.231(6.205)$ & $-0.326(5.741)$ \\
\hline THA Magnum 2 & $0.007(0.001)$ & $0.046(0.026)$ & $0.012(0.002)$ & $0.070(0.036)$ & $2.776(4.635)$ & $0.128(2.342)$ \\
\hline THA Magnum 3 & $0.019(0.003)$ & $0.025(0.032)$ & $0.027(0.004)$ & $0.045(0.040)$ & $1.321(0.359)$ & $3.225(4.458)$ \\
\hline THA Magnum 4 & $0.008(0.002)$ & $0.068(0.102)$ & $0.011(0.003)$ & $0.092(0.117)$ & $0.719(1.681)$ & $-2.305(2.537)$ \\
\hline THA Magnum 5 & $0.033(0.003)$ & $0.038(0.051)$ & $0.047(0.005)$ & $0.062(0.066)$ & $1.655(1.066)$ & $0.382(2.343)$ \\
\hline
\end{tabular}

Mean values with standard deviations shown in brackets

Table IV. Surface roughness $\left(S_{a}, S_{q c}\right.$ and $\left.S_{s k}\right)$ results for the six acetabular components in the unworn and worn regions

\begin{tabular}{|c|c|c|c|c|c|c|}
\hline \multirow[t]{2}{*}{ Joint } & \multicolumn{2}{|l|}{$S_{a}(\mu m)$} & \multicolumn{2}{|l|}{$S_{q c}(\mu m)$} & \multicolumn{2}{|l|}{$S_{\text {sk }}$} \\
\hline & Unworn & Worn & Unworn & Worn & Unworn & Worn \\
\hline Resurfacing & $0.026(0.003)$ & $0.028(0.010)$ & $0.037(0.004)$ & $0.049(0.028)$ & $1.361(0.955)$ & $-0.712(2.080)$ \\
\hline THA Magnum 1 & $0.016(0.002)$ & $0.021(0.005)$ & $0.021(0.003)$ & $0.040(0.012)$ & $0.691(0.301)$ & $-3.642(1.418)$ \\
\hline THA Magnum 2 & $0.024(0.004)$ & $0.034(0.017)$ & $0.030(0.005)$ & $0.061(0.031)$ & $0.539(0.316)$ & $0.629(2.789)$ \\
\hline THA Magnum 3 & NA & $0.034(0.014)$ & NA & $0.059(0.021)$ & NA & $-1.257(2.160)$ \\
\hline THA Magnum 4 & $0.007(0.001)$ & $0.036(0.021)$ & $0.013(0.004)$ & $0.065(0.031)$ & $3.035(8.560)$ & $-2.416(2.240)$ \\
\hline THA Magnum 5 & $0.008(0.001)$ & $0.049(0.032)$ & $0.013(0.003)$ & $0.087(0.054)$ & $1.456(4.308)$ & $-0.466(1.276)$ \\
\hline
\end{tabular}

THA, total hip arthroplasty; NA, data not available

Mean values with standard deviations shown in brackets
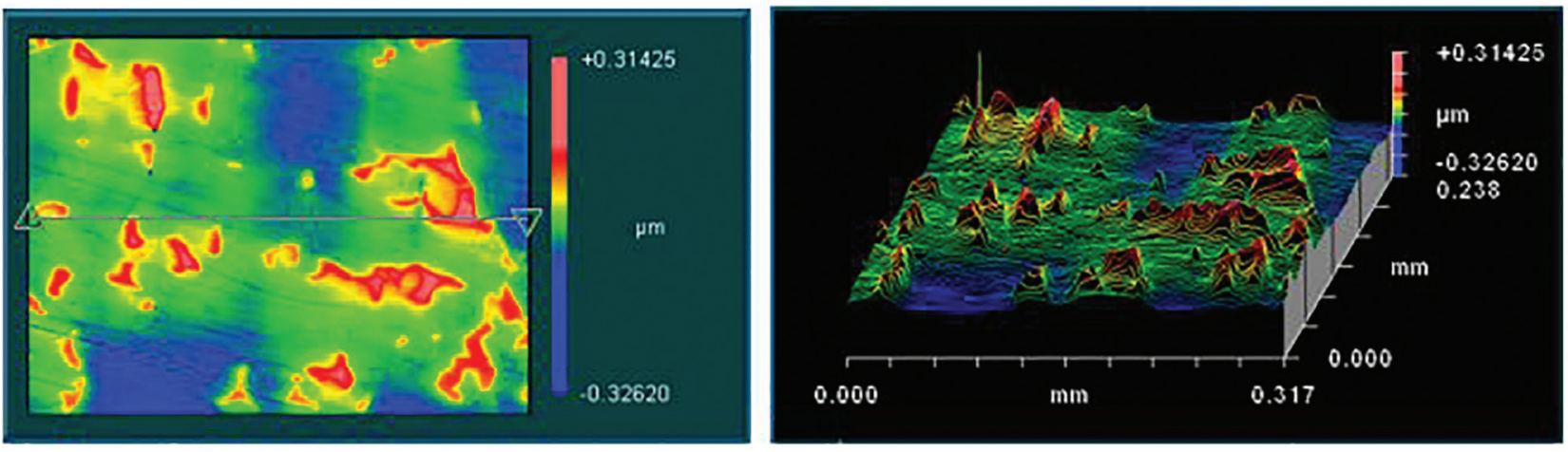

Fig. $3 a$
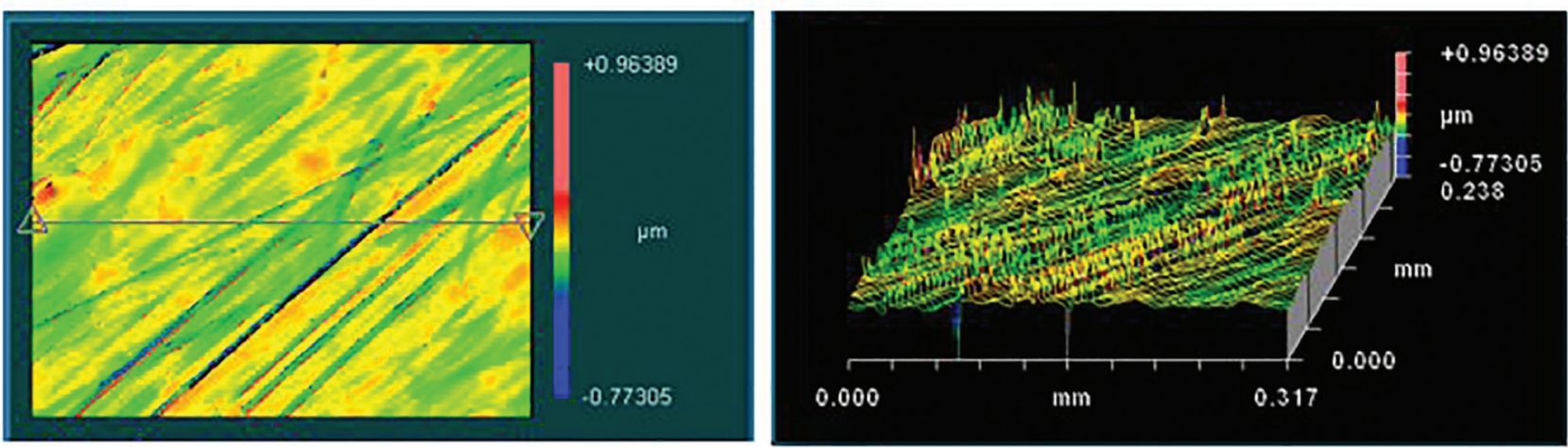

Fig. $3 b$

Surface profilometry images of a femoral head (a) unworn region showing carbides $\left(S_{\mathrm{qh}}: 0.047 \mu \mathrm{m} ; S_{\mathrm{sk}}: 0.929\right)$, and $(\mathrm{b})$ worn region showing scratching $\left(S_{\mathrm{qh}}\right.$ : $0.075 \mu \mathrm{m} ; S_{\mathrm{sk}}: 0.473$ ). 

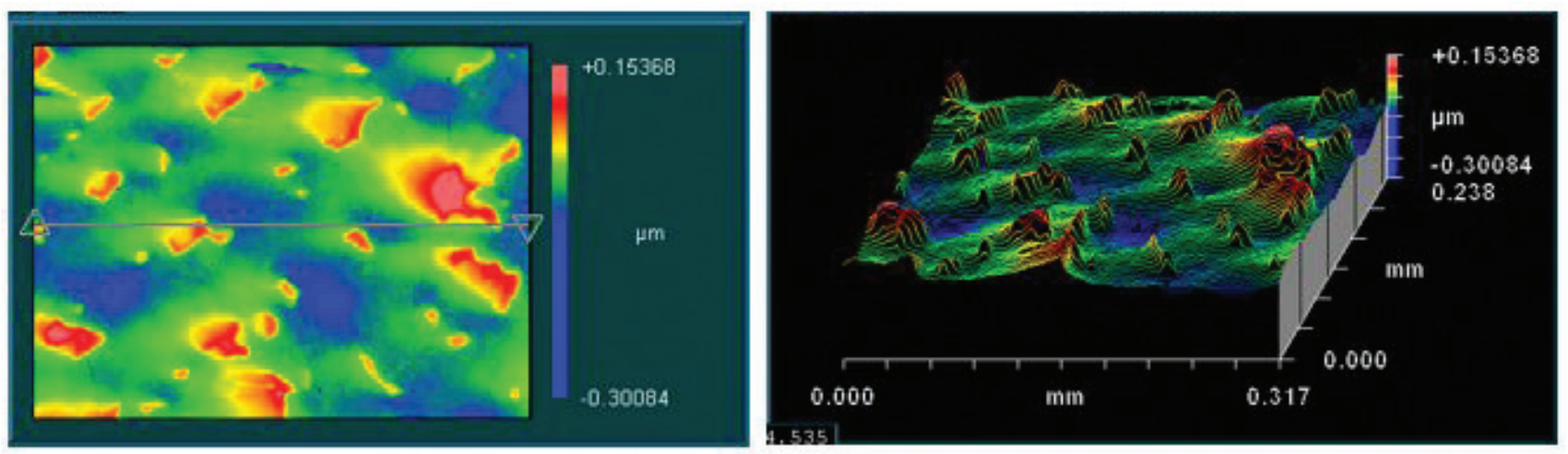

Fig. $4 \mathrm{a}$
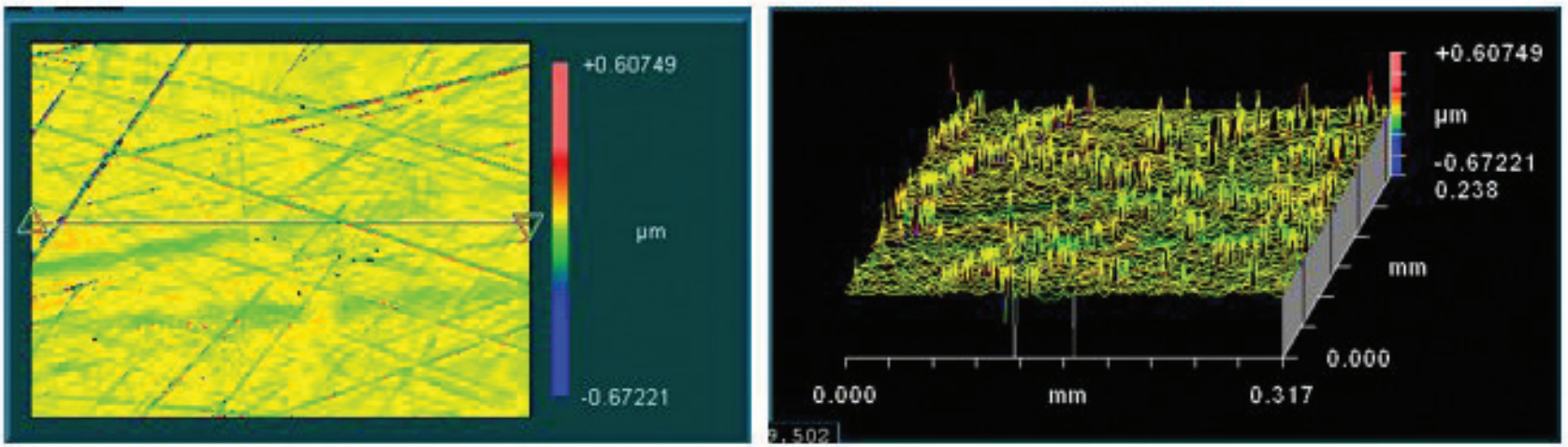

Fig. $4 b$

Surface profilometry images of an acetabular component (a) unworn region showing carbides $\left(S_{\mathrm{qc}}: 0.035 \mu \mathrm{m} ; S_{\mathrm{sk}}: 1.032\right)$ and $(\mathrm{b})$ worn region showing scratch$\operatorname{ing}\left(S_{\mathrm{qc}}: 0.054 \mu \mathrm{m} ; S_{\mathrm{sk}}:-0.112\right)$.

Table V. Predicted minimum film thicknesses $\left(h_{\min }\right)$ and lubrication regimes

\begin{tabular}{|c|c|c|c|c|}
\hline \multirow[t]{2}{*}{ Joint } & \multirow[t]{2}{*}{ Implant diameter (mm) } & \multirow[t]{2}{*}{$h_{\min }(\mu \mathrm{m})$} & \multicolumn{2}{|l|}{$\lambda$} \\
\hline & & & Unworn & Worn \\
\hline Resurfacing & 44 & 0.05 & 0.68 Boundary & 0.78 Boundary \\
\hline THA Magnum 1 & 44 & 0.06 & 2.61 Mixed & 1.14 Mixed \\
\hline THA Magnum 2 & 46 & 0.06 & 1.91 Mixed & 0.67 Boundary \\
\hline THA Magnum 3 & 46 & 0.05 & NA & 0.68 Boundary \\
\hline THA Magnum 4 & 52 & 0.07 & 3.89 Full-fluid film & 0.59 Boundary \\
\hline THA Magnum 5 & 48 & 0.06 & 1.29 Mixed & 0.59 Boundary \\
\hline
\end{tabular}

THA, total hip arthroplasty; NA, data not available

Taper wear. The taper angles and wear volumes measured on the female tapers of the five THA femoral heads are shown in Table VI. The volumetric wear for each of the five Biomet Magnum THA tapers ranged from 0.16 to $0.96 \mathrm{~mm}^{3}$, with a mean total volumetric wear of 0.38 $\mathrm{mm}^{3}$ and a mean wear rate of $0.054 \mathrm{~mm}^{3} /$ year. The maximum wear depths ranged from $4.6 \mu \mathrm{m}$ to $8.5 \mu \mathrm{m}$, with a mean of $5.7 \mu \mathrm{m}$. Indicative images displaying the positioning of the wear on the tapers are shown in Figure 5.

Table VII provides the surface roughness results for the tapers of each THA Magnum femoral head. These were measured in the regions that were engaged with the trunnion when implanted.

\section{Discussion}

For all six explants, wear on the femoral head was localised in a region towards the pole (as illustrated in Fig. 2). The wear area of the acetabular component was positioned mainly at the rim. Variable magnitudes of this edge wear was found on all of the acetabular components measured. The acetabular component inclination angles ranged from $37^{\circ}$ to $45^{\circ}$ (Table I). Surgical 
Table VI. Taper angle and wear data for each femoral head taper

\begin{tabular}{llll}
\hline Joint & Taper angle & Wear $\left.\mathbf{( m m}^{\mathbf{3}}\right)$ & Wear rate $\left(\mathbf{m m} \mathbf{m}^{\mathbf{3}} \mathbf{y r}\right)$ \\
\hline THA Magnum 1 & $4.06^{\circ}$ & 0.19 & 0.026 \\
THA Magnum 2 & $4.09^{\circ}$ & 0.96 & 0.128 \\
THA Magnum 3 & $4.00^{\circ}$ & 0.16 & 0.021 \\
THA Magnum 4 & $4.01^{\circ}$ & 0.24 & 0.041 \\
THA Magnum 5 & $4.02^{\circ}$ & 0.36 & 0.053
\end{tabular}

THA, total hip arthroplasty
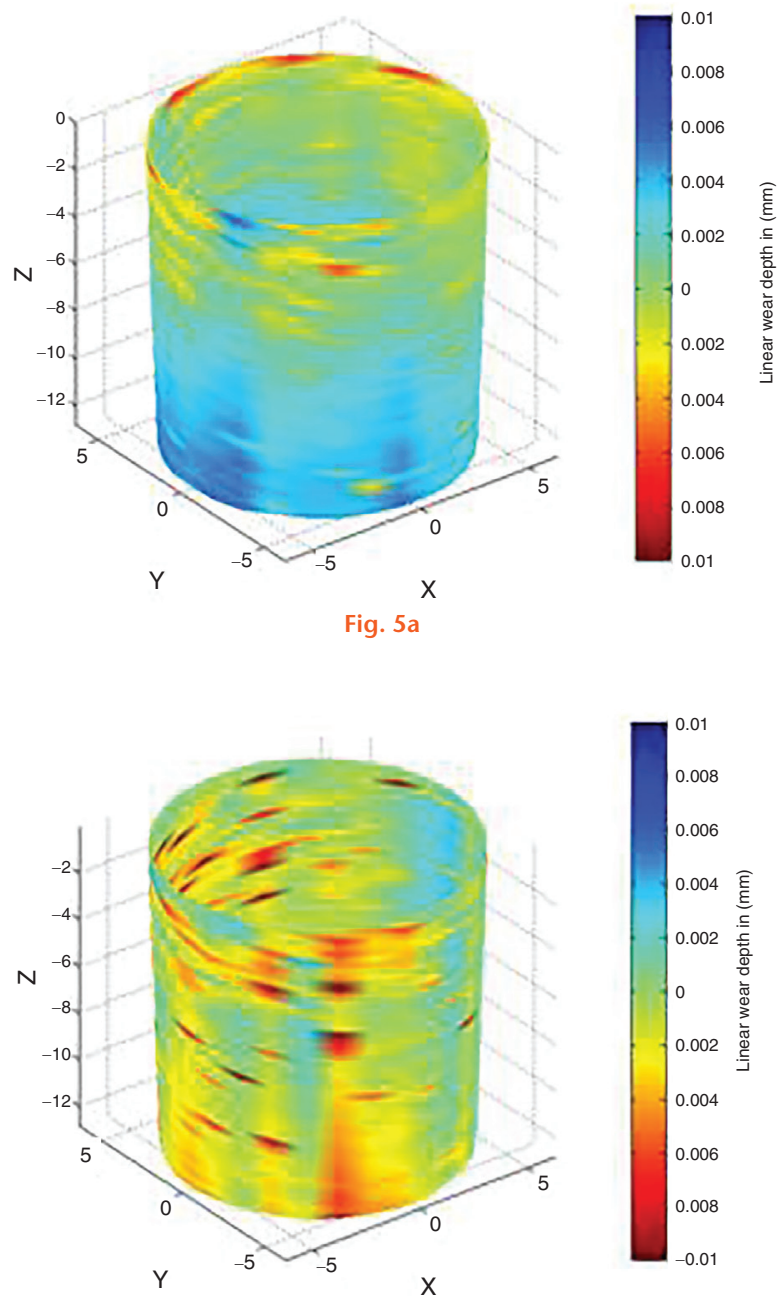

Fig. $5 b$

Images of worn (blue/green) areas on the femoral head tapers of the THAs.

positioning has, therefore, been excluded as the reason for this edge wear. It must be noted, however, that the explant with the lowest acetabular component inclination angle $\left(37^{\circ}\right)$ gave the highest wear, along with high blood metal ion levels; this explant also had the highest radial clearance. Acetabular component edge wear is a common feature with failed MoM hip joints. 4,30

Previous work performed on 57 failed DePuy ASR MoM hip joints ${ }^{6}$ reported that a volumetric wear rate of 2.3 $\mathrm{mm}^{3} /$ year from the articulating surfaces was sufficient to
Table VII. Taper surface roughness measurements $\left(R_{\mathrm{a}}\right.$ and $R_{\mathrm{q}}$ ) (mean values with standard deviations shown in brackets below)

\begin{tabular}{lll}
\hline Joint & $\boldsymbol{R}_{\mathbf{a}}(\boldsymbol{\mu m})$ & $\boldsymbol{R}_{\mathbf{q}}(\boldsymbol{\mu m})$ \\
\hline THA Magnum 1 & $0.286(0.016)$ & $0.349(0.019)$ \\
THA Magnum 2 & $0.707(0.124)$ & $0.868(0.138)$ \\
THA Magnum 3 & $1.177(0.129)$ & $1.331(0.136)$ \\
THA Magnum 4 & $0.803(0.087)$ & $0.957(0.090)$ \\
THA Magnum 5 & $0.319(0.063)$ & $0.398(0.094)$ \\
\hline
\end{tabular}

THA, total hip arthroplasty

Table VIII. Revision rates for metal-on-metal total hip arthroplastys ${ }^{2}$

\begin{tabular}{llll}
\hline Manufacturer & $\begin{array}{l}\text { Femoral } \\
\text { component }\end{array}$ & $\begin{array}{l}\text { Acetabular } \\
\text { component }\end{array}$ & $\begin{array}{l}\text { Cumulative } \\
\text { percentage } \\
\text { revision at 7 yrs }\end{array}$ \\
\hline Smith \& Nephew & Synergy & BHR & 7.4 \\
Biomet & Taperloc & ReCap & 8.6 \\
Zimmer & Alloclassic & Durom & 10.4 \\
DePuy & Summit & ASR & 32.4 \\
DePuy & Corail & ASR & 38.7 \\
\hline
\end{tabular}

BHR, Birmingham Hip Resurfacing; ASR, articular surface replacement

cause revision due to ARMD (the range of wear rates was $2.3 \mathrm{~mm}^{3} /$ year to $95.5 \mathrm{~mm}^{3} /$ year). The wear rates of each of these THA and surface replacement ReCap joints (4.1 to $7.6 \mathrm{~mm}^{3}$ /year) fall within this range. Published work posing a view on wear rates of MoM hips sufficient to lead to revision has been available for many years. In 2003, 22 explanted MoM hips of $28 \mathrm{~mm}$ diameter were measured to have a mean wear rate of $2.02 \mathrm{~mm}^{3} /$ year (0.55 to 3.74). ${ }^{31}$ It was reported that these joints were revised for early aseptic loosening. Therefore, it could have been argued in 2003 that a wear rate of more than $0.55 \mathrm{~mm}^{3} /$ year was sufficient to cause failure of a MoM hip.

The cumulative percentage probability of revision for the Biomet ReCap resurfacing replacement joint is shown in the 2016 National Joint Registry (NJR) as 7.79\% at seven years. This compares with $5.47 \%$ for the BHR and 20.88\% for the ASR. ${ }^{7}$ In the Australian Orthopaedic Association (AOA) National Joint Registry Annual Report 2015, the Biomet ReCap resurfacing has a revision rate of $12.2 \%$ at seven years. ${ }^{32}$ It is clear that the Biomet ReCap resurfacing replacement has a lower revision rate than the DePuy ASR, and this may be because they are "not susceptible to the same design problems' as the ASR. ${ }^{20}$ This may be due to the larger arc of cover provided by the 
acetabular components. It has been shown $n^{4,8}$ that the ASR has a lower arc of cover $\left(151^{\circ}\right.$ for a $52 \mathrm{~mm}$ diameter joint) than the BHR (162 for a $52 \mathrm{~mm}$ joint). The arc of cover of the Biomet ReCap resurfacing joint ranges from $154.6^{\circ}$ for a $38 \mathrm{~mm}$ diameter implant to $163.6^{\circ}$ for the 60 $\mathrm{mm}$ diameter implant. ${ }^{20}$

With regard to the Magnum/ ReCap/ Taperloc THA, the AOA Registry showed the cumulative percentage revision as $8.6 \%$ at seven years. ${ }^{32}$ No data were available on the Magnum/ ReCap/ Taperloc THA in the NJR. ${ }^{7}$ Table VIII shows the cumulative percentage revision of MoM primary THAs at seven years from the Australian Joint Registry. It can be seen that, in comparison with alternative designs, the Magnum/ ReCap/ Taperloc produced only slightly higher cumulative percentage rates of revision at seven years than the BHR.

The revision rates stated in the NJR for MoM THAs are higher than those for the MoM hip resurfacings. ${ }^{7}$ The reasons for this were investigated 6,8 and it was concluded that wear at the modular junction between the head taper and trunnion of the stem in the DePuy ASR and the DePuy 36 mm diameter MoM Pinnacle Articuleze joints can result in ARMD. Any taper wear will add to the wear produced at the articulating surfaces and lead to greater failure rates of THA. ${ }^{6}$

The taper wear measurements for the Ti taper of the Biomet Magnum THAs (mean: $0.05 \mathrm{~mm}^{3} /$ year) were low compared with those measured for the $\mathrm{CoCr}$ tapers of the DePuy ASR XL (mean: $2.60 \mathrm{~mm}^{3} /$ year) and DePuy Pinnacle Articuleze prostheses (mean $2.80 \mathrm{~mm}^{3} /$ year). ${ }^{8}$ The wear results displayed in Table $V$ show the low taper wear for this Ti/Ti taper junction in this study. In fact, the wear measurements on the tapers of three of the joints (THA Magnum 1, 3 and 5) were close to or below the 0.2 $\mathrm{mm}^{3}$ accuracy limit of the CMM used for these taper wear measurements. So why did these Biomet joints provide such low taper wear? This may be due to the material combination used at the taper junction; Ti/Ti junctions used with the THA Magnums have been shown to provide lower wear than the $\mathrm{Ti}$ stem/CoCr head taper used with the ASR XL and Pinnacle. ${ }^{33}$ However, this should not be seen as a panacea as similar materials can 'cold weld' and show adhesive wear. Other factors may also be involved. It appears that the taper design used with the Biomet Magnum joints has reduced the wear at the taper junction compared with other designs. It is appreciated that any material released at this $\mathrm{Ti} / \mathrm{Ti}$ taper junction will not have contributed to the $\mathrm{Co}$ and $\mathrm{Cr}$ metal ion levels measured. Thus, for the Biomet ReCap explants analysed in this study, failure was due to ARMD likely caused by wear from the articulating surfaces, not the femoral head tapers.

In summary, the wear rates for the five retrieved Biomet Magnum/ ReCap/ Taperloc THAs and one Biomet ReCap resurfacing hip joint were higher than those considered to be able to cause wear-related failures in similar large diameter monoblock MoM hips $\left(2.3 \mathrm{~mm}^{3} /\right.$ year). The wear of the joints measured in this study was mainly found to be from the articulating surfaces. The authors believe that patients implanted with the Biomet ReCap system should be monitored.

\section{References}

1. McMinn D, Treacy R, Lin K, Pynsent P. Metal on metal surface replacement of the hip. Experience of the McMinn prothesis. Clin Orthop Relat Res 1996;329 Suppl:S89-S98.

2. Skipor AK, Campbell PA, Patterson LM, et al. Serum and urine metal levels in patients with metal-on-metal surface arthroplasty. J Mater Sci Mater Med 2002;13:1227-1234

3. Dunbar MJ, Prasad V, Weerts B, Richardson G. Metal-on-metal hip surface replacement: the routine use is not justified. Bone Joint J 2014;96-B:17-21.

4. Langton DJ, Jameson SS, Joyce TJ, et al. Early failure of metal-on-metal bearings in hip resurfacing and large-diameter total hip replacement: a consequence of excess wear. J Bone Joint Surg [Br] 2010;92-B:38-46.

5. Kwon YM, Glyn-Jones S, Simpson DJ, et al. Analysis of wear of retrieved metalon-metal hip resurfacing implants revised due to pseudotumours. J Bone Joint Surg [Br]2010;92-B:356-361.

6. Langton DJ, Jameson SS, Joyce TJ, et al. Accelerating failure rate of the ASR total hip replacement. J Bone Joint Surg [Br] 2011;93-B:1011-1016.

7. No authors listed. National Joint Registry for England, Wales, Northern Ireland and the Isle of Man. 13th Annual Report, 2016. http://www.njrcentre.org.uk/njrcentre/ Portals/0/Documents/England/Reports/13th\%20Annual\%20Report/07950\%20 NJR\%20Annual\%20Report\%202016\%200NLINE\%20REPORT.pdf (date last accessed 15 December 2016

8. Langton DJ, Sidaginamale R, Lord JK, et al. Taper junction failure in largediameter metal-on-metal bearings. Bone Joint Res 2012;1:56-63.

9. Brock TM, Sidaginamale R, Rushton S, et al. Shorter, rough trunnion surfaces are associated with higher taper wear rates than longer, smooth trunnion surfaces in a contemporary large head metal-on-metal total hip arthroplasty system. J Orthop Res 2015;33:1868-1874

10. Sidaginamale RP, Joyce TJ, Bowsher JG, et al. The clinical implications of metal debris release from the taper junctions and bearing surfaces of metal-on-metal hip arthroplasty: joint fluid and blood metal ion concentrations. Bone Joint J 2016;98B:925-933

11. Naal FD, Pilz R, Munzinger $\mathbf{U}$, et al. High revision rate at 5 years after hip resurfacing with the Durom implant. Clin Orthop Relat Res 2011;469:2598-2604.

12. Matharu GS, Theivendran K, Pynsent PB, et al. Outcomes of a metal-on-metal total hip replacement system. Ann R Coll Surg Eng/2014;96:530-535.

13. No authors listed. MHRA. Medical Device Alert MDA/2015/024. Metal-on-metal (MoM) hip replacements: Birmingham Hip Resurfacing (BHR) system. Smith \& Nephew Orthopaedics; 2015 https://www.gov.uk/drug-device-alerts/metal-onmetal-mom-hip-replacements-guidance-on-implantation-and-patient-management (date last accessed 08 February 2017).

14. Smith AJ, Dieppe P, Howard PW, Blom AW, National Joint Registry for England and Wales. Failure rates of metal-on-metal hip resurfacings: analysis of data from the National Joint Registry for England and Wales. Lancet 2012;380:1759-1766.

15. Gross TP, Liu F, Webb LA. Clinical outcome of the metal-on-metal hybrid Corin Cormet 2000 hip resurfacing system: an up to 11-year follow-up study. J Arthroplasty 2012;27:533-538.

16. Matharu GS, Pandit HG, Murray DW, Treacy RBC. The future role of metal-onmetal hip resurfacing. Int Orthop 2015;39:2031-2036.

17. No authors listed. National Institute for Health and Care Excellence. Total hip replacement and resurfacing arthroplasty for end-stage arthritis of the hip. NICE technology appraisal guidance [TA304], February 2014: https://www.nice.org.uk/ guidance/ta304/chapter/1-Guidance (date last accessed 15 December 2016).

18. Lord JK, Langton DJ, Nargol AVF, Joyce TJ. Volumetric wear assessment of failed metal-on-metal hip resurfacing prostheses. Wear 2011;272:79-87.

19. Jennings LM, Al-Hajjar M, Brockett CL, et al. (iv) Enhancing the safety and reliability of joint replacement implants. Orthop Trauma 2012;26:246-252.

20. Gross TP, Liu F. Hip resurfacing with the Biomet Hybrid ReCap-Magnum system: 7-year results. J Arthroplasty 2012;27:1683-1689. 
21. No authors listed. Biomet Europe. ReCap ${ }^{T M}$ Design Rationale, ReCap ${ }^{T M}$ Resurfacing Hip System. http://www.biomet.co.uk/resource/16068/FLH174\%20ReCap\%20 Design\%20Rationale.pdf (date last accessed 16 December 2016).

22. Langton DJ, Sidaginamale RP, Holland JP, et al. Practical considerations for volumetric wear analysis of explanted hip arthroplasties. Bone Joint Res 2014;3:60-68.

23. Joyce TJ, Langton DJ, Jameson SS, Nargol AVF. Tribological analysis of failed resurfacing hip prostheses and comparison with clinical data. Proc Inst Mech Eng, Part J J Eng Tribo/ 2009;223:317-323.

24. Joyce TJ, Grigg H, Langton DJ, Nargol AVF. Quantification of self-polishing in vivo from explanted metal-on-metal total hip replacements. Tribol Int 2011;44:513-516.

25. Lord JK, Langton DJ, Nargol AVF, et al. The Tribology of Explanted Hip Resurfacings Following Early Fracture of the Femur. J Funct Biomater 2015;6:1021-1035.

26. Hamrock BJ, Dowson D. Elastohydrodynamic Lubrication of Elliptical Contacts for Materials of Low Elastic-Modulus I - Fully Flooded Conjunction. Journal of Lubrication Technology-Transactions of the Asme 1978;100:236-245.

27. Johnson KL, Greenwood JA, Poon SY. A simple theory of asperity contact in elastohydro-dynamic lubrication. Wear 1972;19:91-108.

28. Scholes SC, Unsworth A. Comparison of friction and lubrication of different hip prostheses. Proc Inst Mech Eng H2000;214:49-57.

29. Scholes SC, Unsworth A. The effect of proteins on the friction and lubrication of artificial joints. Proc Inst Mech Eng H2006;220:687-693.

30. Morlock MM, Bishop N, Zustin J, et al. Modes of implant failure after hip resurfacing: morphological and wear analysis of 267 retrieval specimens. J Bone Joint Surg [Am]2008;90-A:89-95.

31. Reinisch G, Judmann KP, Lhotka C, et al. Retrieval study of uncemented metal-metal hip prostheses revised for early loosening. Biomaterials 2003;24:1081-1091.

32. No authors listed. Australian Orthopaedic Association National Joint Replacement Registry Hip and Knee Arthroplasty 2015 Annual Report, in https://www.aoa.org.au/ about-aoa/resources/annual-reports (date last accessed 08 February 2017).
33. Nassif NA, Nawabi DH, Stoner K, et al. Taper design affects failure of large-head metal-on-metal total hip replacements. Clin Orthop Relat Res 2014;472:564-571.

Funding Statement

- This research was funded internally by Newcastle University.

- A grant has also been received by North Bristol NHS Trust from Biomet UK to monitor the performance of the ReCap Magnum device.

E. Smith reports a Consultant and Royalty Agreement (2005 to July 2016) with Biomet UK for the Exceed and Exceed ABT Acetabular Cup System.

- T Joyce has provided expert testimony in relation to metal-on-metal hips, this is not related to this article.

D. J. Langton has received funding in relation to consultancy, employment, and expert testimony from plaintiff lawyers in relation to metal-on-metal hip litigation the money was paid to D. J. Langton's company, PXD Ltd, of which he is director. PXD is also in receipt of a grant to investigate hip taper junction failure, as well as a patent for an acetabular alignment guide.

Author Contribution

S. C. Scholes: Preparation of study plan, Testing, Data collection, Data analysis, Writing the paper.

B. J. Hunt: Surface roughness testing on the tapers

V. M. Richardson: Composition of manuscript and management of data.

D. I. Langton: Assistance with experimental technique, Writing the paper.

E. Smith: Data analysis and composition of paper

- T. J. Joyce: Preparation of study plan, Data analysis, Writing the paper.

ICMJE Conflicts of Interest

D. J. Langton states that he is currently involved in "Personal litigation against Depuy in the United States. Possible financial reward. I do not believe this has any relevance to this manuscript however."

- Dr Smith reports a grant from Biomet UK Limited to his institution - North Bristol NHS Trust - during the conduct of the study as well as a former relationship with Biomet UK Limited outside the submitted work.

(c) 2017 Scholes et al. This is an open-access article distributed under the terms of the Creative Commons Attributions licence (CC-BY-NC), which permits unrestricted use, distribution, and reproduction in any medium, but not for commercial gain, provided the original author and source are credited. 